\title{
Electronically assisted surveillance systems of healthcare-associated infections: a systematic review
}

H Roel A Streefkerk ${ }^{1,2}$, Roel PAJ Verkooijen ${ }^{3}$, Wichor M Bramer ${ }^{4}$, Henri A Verbrugh ${ }^{1}$

1. Erasmus University Medical Center (Erasmus MC), Rotterdam, the Netherlands

2. Albert Schweitzer Hospital/Rivas group Beatrix hospital/Regionaal Laboratorium medische Microbiologie, Dordrecht/ Gorinchem, the Netherlands

3. Department of Medical Microbiology, University of Groningen, University Medical Center Groningen, Groningen, the Netherlands

4. Medical Library, Erasmus MC University Medical Center Rotterdam, Rotterdam, the Netherlands

Correspondence: Roel Streefkerk (r.streefkerk@asz.nl)

Streefkerk H Roel A, Verkooijen Roel PAJ, Bramer Wichor M, Verbrugh Henri A. Electronically assisted surveillance systems of healthcare-associated infections: a systematic review. Euro Surveill. 2020;25(2):pii=1900321. https://doi.org/10.2807/1560-7917.ES.2020.25.2.1900321

Background: Surveillance of healthcare-associated infections (HAI) is the basis of each infection control programme and, in case of acute care hospitals, should ideally include all hospital wards, medical specialties as well as all types of HAI. Traditional surveillance is labour intensive and electronically assisted surveillance systems (EASS) hold the promise to increase efficiency. Objectives: To give insight in the performance characteristics of different approaches to EASS and the quality of the studies designed to evaluate them. Methods: In this systematic review, online databases were searched and studies that compared an EASS with a traditional surveillance method were included. Two different indicators were extracted from each study, one regarding the quality of design (including reporting efficiency) and one based on the performance (e.g. specificity and sensitivity) of the EASS presented. Results: A total of 78 studies were included. The majority of EASS $(n=72)$ consisted of an algorithm-based selection step followed by confirmatory assessment. The algorithms used different sets of variables. Only a minority $(n=7)$ of EASS were hospital-wide and designed to detect all types of HAI. Sensitivity of EASS was generally high (>0.8), but specificity varied $(0.37-1)$. Less than $20 \%(n=14)$ of the studies presented data on the efficiency gains achieved. Conclusions: Electronically assisted surveillance of HAl has yet to reach a mature stage and to be used routinely in healthcare settings. We recommend that future studies on the development and implementation of EASS of HAI focus on thorough validation, reproducibility, standardised datasets and detailed information on efficiency.

\section{Introduction}

Surveillance of healthcare-associated infections ( $\mathrm{HAl}$ ) entails the systematic collection of data on the presence of HAl, analysis and transformation of the data into information and sharing this information with those who can take action to prevent HAI. Surveillance with feedback is a key/core component for effective infection prevention and control in the strategies of both the World Health Organization (WHO) and the European Centre for Disease Prevention and Control $(E C D C)[1,2]$. Surveillance and epidemiology are the first criteria included in the minimum standard of practice of an infection preventionist (Association for Professionals in Infection Control and Epidemiology (APIC) 2016 professional and practice standards). They are also a core task according to the Dutch society of Hygiene and Prevention in Healthcare (VHIG 2014, professional profile). The Health and Social Care Act 2008 code of practice of the prevention and control of infections and related guidance (2015, United Kingdom) likewise states that there should be evidence of local surveillance and of the use of comparative data, where available, to monitor infection rates in healthcare settings. In 2005, legislation on mandatory reporting of HAl had already been enacted in 35 states of the United States. In 2008, the Centers for Medicare and Medicaid Services stopped additional payment to hospitals to cover for the costs of treating mediastinitis after coronary artery bypass graft surgery, because this HAI was deemed to be preventable by HAI surveillance and control. Likewise, surgical site infection (SSI) after specific orthopaedic procedures and bariatric surgery were not covered anymore. This change reflected the importance of $\mathrm{HAl}$ surveillance and prevention. Hospital accrediting authorities, including Joint Commission International, also recognise the importance of surveillance activities. 
TABLE 1

Categorisation of the electronically assisted surveillance system's algorithms based on the set of variables included

\begin{tabular}{|l|l|}
\hline Category & \multicolumn{1}{|c|}{ Description } \\
\hline 1 & ICD coding only \\
\hline 2 & Microbiology (bacterial, viral, fungal pathogens detected by culture, molecular or serological diagnostics) \\
\hline 3 & Microbiology + antibiotic prescriptions \\
\hline 4 & Microbiology + antibiotic prescriptions + clinical chemistry \\
\hline 5 & $\begin{array}{l}\text { Other (body temperature OR/AND judgement by physician OR/AND ventilator setting OR/AND fuzzy logic or natural language } \\
\text { processing of clinical notes OR/AND risk factors, like indwelling catheters) }\end{array}$ \\
\hline
\end{tabular}

ICD: International Classification of Diseases.

Surveillance in its traditional format, in which every patient's record is assessed on the presence of $\mathrm{HAl}$, is labour intensive and can take up to 756 manhours for a point prevalence survey or an estimated 1.5 fulltime equivalent (FTE) per 10,000 admissions [3,4]. Surveillance of $\mathrm{HAl}$ should ideally include all hospital wards, medical specialties as well as all types of HAl, such that fully informed, evidence-based decisions can be made to prioritise and structurally address the relevant infection issues of the particular healthcare setting. However, in the face of limited resources, available labour intensive manual surveillance systems have driven most healthcare centres to apply so-called targeted forms of surveillance that include only high risk wards and/or few types of medical procedures and/or only a few types of $\mathrm{HAl}$.

Alternatively, efforts have been made to significantly improve the efficiency (i.e. reducing the time spent on surveillance while obtaining the same results) of $\mathrm{HAl}$ surveillance by applying information technologies to query data routinely available in hospital electronic databases. With the ongoing application of new information technologies in healthcare, the types and sizes of these electronic databases have been increasing over the last decades. It is, however, unclear what level of efficiency and accuracy (i.e. proportion of individuals truly positive and negative for an $\mathrm{HAl}$ ) has been attained so far by applying these newer electronic information sources and technologies. Increasing the efficiency of surveillance can be achieved by introducing a computerised algorithm-based selection of highrisk patients followed by confirmatory assessment of the selected cases by the infection control practitioner (ICP) (semi-automated electronically assisted surveillance system (EASS)). Alternatively, surveillance can be based on the outcome of a computerised algorithm alone, without confirmation of individual cases by the ICP (fully automated EASS).

With this systematic review, we aim to give insight in the current status of EASS by assessing their performance (sensitivity and specificity) compared with traditional surveillance, the variables used in the electronic algorithms and the quality of the studies (including efficiency) that presented and evaluated them.

\section{Methods}

\section{Inclusion of articles}

In this systematic review, the Preferred Reporting Items for Systematic Reviews and Meta-Analyses (PRISMA) guidelines were followed [5]. The following online databases were searched on 10 January 2018: Embase, Medline Ovid, Cochrane, Web of Science, Scopus, CINAHL (EBSCOhost) and Google Scholar. The Embase search was the basis for the search method and then translated for use in other databases. All publications, except grey literature, in the past up to 10 January 2018 were included. The full description of the queries per database is provided in the supplementary material. The process of identification, screening and inclusion of articles for full text synthesis is consistent with the method described by Bramer et al. [6-8]. In brief, this method consists of a query in online databases, review of all the abstracts by two reviewers independently to screen for articles that probably meet the inclusion criteria (eligible) followed by full article review to decide whether an article is included based on the inclusion and exclusion criteria. Included were studies which systematically evaluated the performance of an electronically assisted or fully automated surveillance method against the gold standard (expert opinion of the ICPS based on the United States Centers for Disease Control and Prevention-based criteria for $\mathrm{HAl}$ [9]), and reported at least one performance metric (e.g. sensitivity, specificity). Exclusion criteria were potential incorporation bias, non-English language studies and poster or conference abstracts.

\section{Data collection process}

Using a standardised format, we abstracted the following reported information from each study: (i) year of publication, country and setting; (ii) the study type, population characteristics and sample size; (iii) the type of $\mathrm{HAl}$ (bloodstream infections (BSIs), lower respiratory tract infections (LRTIS), SSIs or urinary tract infections (UTIS)) targeted for surveillance, likewise the medical specialties or wards that were participating in the surveillance effort; (iv) the sensitivity, specificity, positive and negative predictive value, accuracy of the EASS; and (v) all variables that were used in their algorithms. Missing information was not checked with the authors. 
TABLE 2

Quality of study designs: indicators used to evaluate the level of quality of study designs investigating an electronically assisted surveillance system

\begin{tabular}{|c|c|}
\hline Indicator - description & Points awarded \\
\hline \multicolumn{2}{|l|}{ Indicator 1 - validation and test cohort } \\
\hline The study population consisted of a validation cohort and a separate development cohort & 5 \\
\hline The study population consisted of a validation cohort & 3 \\
\hline The study population consisted of a development cohort only & 1 \\
\hline \multicolumn{2}{|l|}{ Indicator 2 - reported context of study } \\
\hline The observed prevalence or incidence of HAl in the healthcare institute was presented in the article & 5 \\
\hline Prevalence or incidence of HAI was not presented in the article & 0 \\
\hline \multicolumn{2}{|l|}{ Indicator 3 - departments under surveillance for $\mathrm{HAI}$} \\
\hline EASS was hospital-wide and included all wards or departments & 5 \\
\hline EASS was not hospital-wide but included $>2$ departments or wards & 3 \\
\hline EASS was targeted to one department or ward only & 1 \\
\hline \multicolumn{2}{|l|}{ Indicator 4 - types of HAI under surveillance } \\
\hline EASS targeted all types of HAI & 5 \\
\hline EASS targeted $>2$ types of HAI & 3 \\
\hline EASS targeted one or two types of HAI only & 1 \\
\hline \multicolumn{2}{|l|}{ Indicator 5 - performance characteristics reported } \\
\hline Sensitivity, specificity and other performance characteristics of the EASS algorithm were presented & 5 \\
\hline Only sensitivity and specificity were presented & 3 \\
\hline Only sensitivity was presented & 1 \\
\hline \multicolumn{2}{|l|}{ Indicator 6 - efficiency reported } \\
\hline Time reduction was presented quantitatively & 5 \\
\hline Workload reduction was presented & 3 \\
\hline No data on workload or time reduction presented & 1 \\
\hline
\end{tabular}

HAI: healthcare-associated infection; EASS: electronically assisted surveillance system.

The red colour represents poor quality, the orange intermediate quality and green indicates good quality.

\section{Algorithm categories}

For each study, we assigned the respective algorithm used to one of the categories based on the variables included as presented in Table 1.

\section{Overall quality and performance score}

Two different scores were calculated based on the data extracted from each study, one regarding the reported design of the study and one regarding the performance of the EASS presented. First, to assess the quality of the design we scored six indicators that represent different aspects of the design of the study. As an example, for indicator 1 , the rationale was as follows: an EASS should be evaluated in a set of patients that is independent of the set used to develop the automated method, as recommended by Govindan et al. in 2010 [10]. Thus when the study population consisted of a validation cohort and a separate development cohort this was considered better ( 5 points) than when the study population consisted of a development cohort only (1 point). Subsequently we calculated an overall quality score by adding up the points assigned for each of the six quality indicators presented in Table 2.

Secondly, for each study we calculated an overall performance score of the EASS presented in the study by multiplying its published sensitivity and specificity. This overall performance score is primarily based on the sensitivity and specificity to detect all types of HAl. If not all types of $\mathrm{HAl}$ were included we calculated an overall performance score based on the means of the sensitivities and specificities specified for the types of $\mathrm{HAl}$ that were included in the study.

\section{Ethical statement}

Ethical approval was not applicable for this review of published literature.

\section{Results}

The online databases search identified 2,410 records after de-duplication, of which 78 studies $[3,4,11-86]$ were included in this systematic review (Figure 1 ).

\section{Timeline and geographical distribution}

Of the 78 identified studies, 30 were from Europe, six from Asia, one from South America and the remaining 41 from North America. The first articles about EASS of $\mathrm{HAl}$ originated in North America and were published in the 1980 s and 1990s. Thereafter, their number increased gradually, involving European centres since the turn of the century, and, more recently centres in 
A flowchart of the inclusion process of studies used in the systematic review (adjusted from the PRISMA 2009 flowchart)
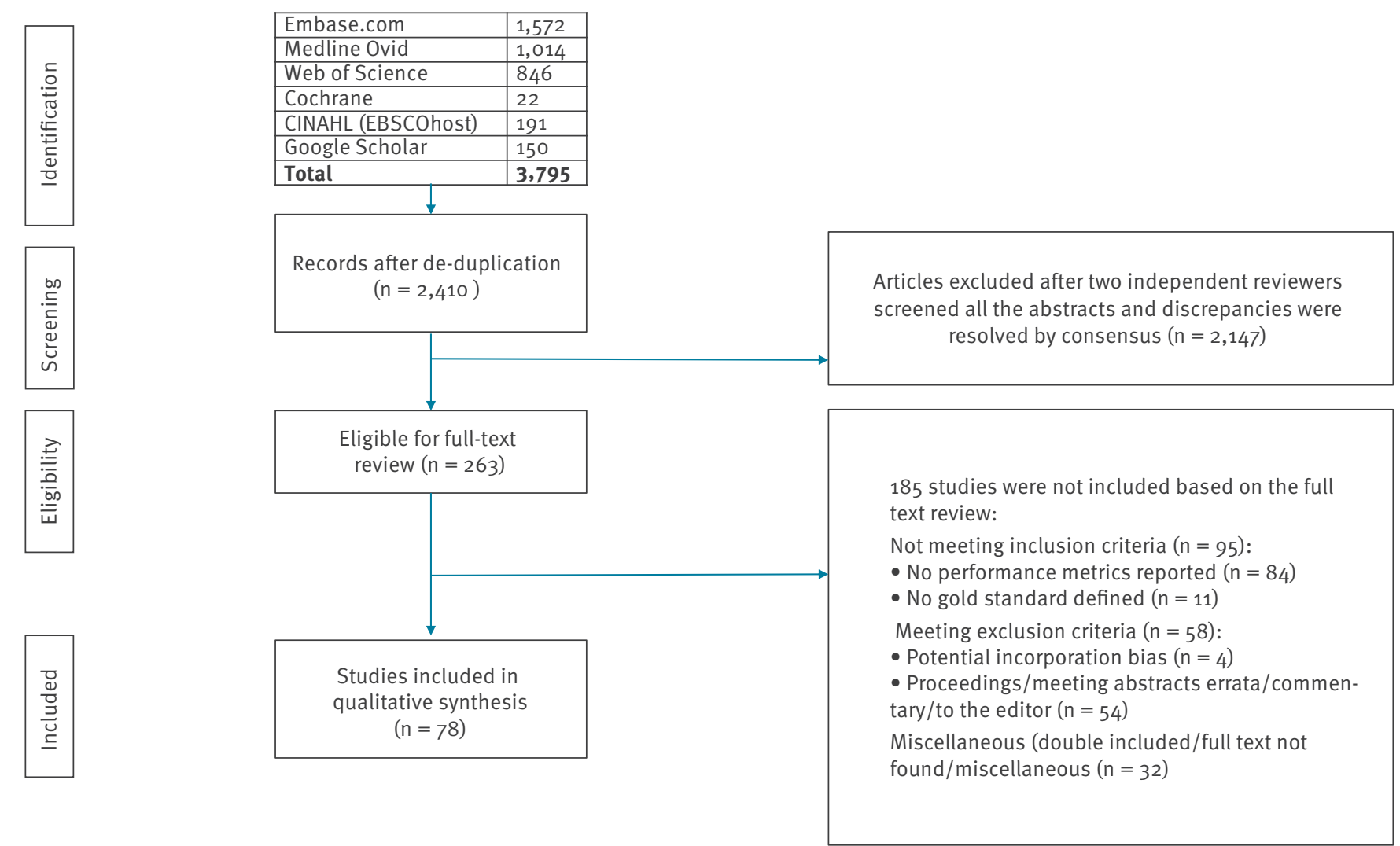

PRISMA: Preferred Reporting Items for Systematic Reviews and Meta-Analyses.

other parts of the world; a peak in the annual number of published articles was reached in 2014 (Figure 2).

In the earliest identified study, in 1986, Evans et al. [30] presented the results of HAI surveillance through their Health Evaluation through Logical Processing (HELP) system at the Latter Day Saints hospital, Salt Lake City, Utah. These pioneers showed that more HAI were found with this EASS, while its execution required only $35 \%$ of the time. In follow-up studies HELP was used to evaluate algorithms to predict infections even before onset of symptoms [29]. It was not until the year 2003 that the first European study was published describing the performance of an EASS; this EASS was implemented in 1998 in a university affiliated teaching hospital in France [11]. From 2000 to 2009 predominantly American and European research groups presented their EASS in the international peer-reviewed literature. In the year 2006, Brossette et al. [4] published the first results of their EASS that used a laboratory-based algorithm, called Nosocomial Infection Marker (NIM), to help identify patients with HAl. This software was the first to become commercially available. From 2010 on, the numbers of publications increased and peaked in 2014. Contributions originating from South America
[56] and Asia $[3,24,50,67,68,77]$ showed that by that time EASS of HAl had adopters worldwide.

Fully- vs semi-automated surveillance

Only six of the 78 studies ( $8 \%$ ) present a fully automated surveillance method $[20,27,52,62,65,69]$, with sensitivities ranging from 0.6 to 0.94 for UTIs and ventricular drain infections respectively.

\section{Quality}

As for indicator 1 of the overall quality score (Table 2), 18 of the $78(23 \%)$ articles included in this review used a development and separate validation cohort. The majority of articles ( 53 of 78 ) clearly presented the point prevalence or incidence of the HAl in the population they studied (quality indicator 2, Table 2). The EASS was hospital-wide (maximum points for quality indicator 3, Table 2) and included all types of HAl (maximum points for quality indicator 4 , Table 2 with at least the 'big four' types of HAI, i.e. BSIs, LRTIs, UTIs and SSIs) in nine of the 78 studies. Just under $40 \%(31 / 78)$ of the studies presented performance characteristics other than only sensitivity and specificity (maximum points for indicator 5). Less than $20 \%(14 / 78)$ of the studies presented the actual time reduction that was achieved by introducing an EASS for HAI (maximum points for 


\section{FIGURE 2}

Published studies on electronically assisted surveillance of healthcare-associated infections by year of publication and by region of the world $(n=78)$

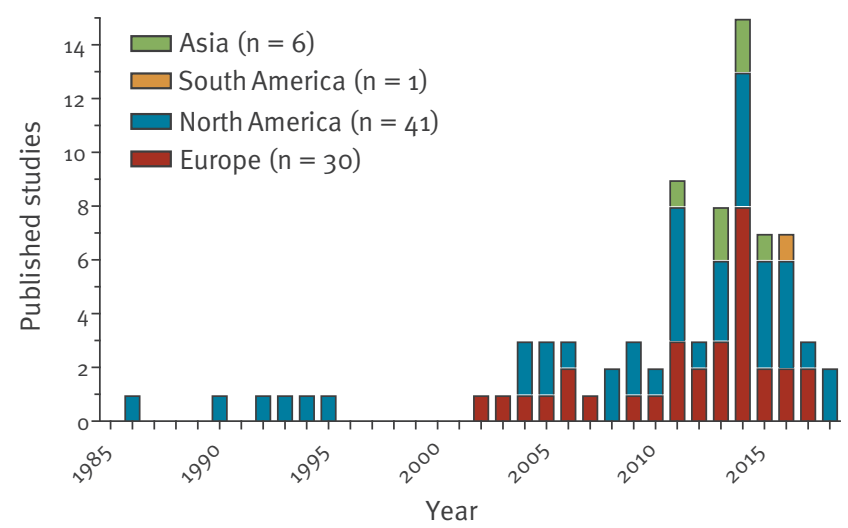

indicator 6, Table 2). None of the articles attained the maximum score (all six indicators 'green or maximum points appointed') and, interestingly, the overall quality score did not seem to improve over the years (supplementary material Table 1).

\section{Performance of electronically assisted} surveillance systems per type of healthcareassociated infection

EASS were most extensively developed and applied in intensive care unit (ICU) settings (44 of the 78 articles included in this review); 20 articles describe an EASS that was developed exclusively for the ICU and targeted the ICU's two most common HAI (ventilator associated pneumonia (VAP) and central line associated BSIs (CLABSI)) [15,18,27,28,32,33,38,40,42,43,51, $52,55,57,61,62,73,75,78,81]$. Other studies focused on one particular type of HAl (one or more of the 'big four': LRTIS, BSIs, SSIs and UTIS) and aimed to facilitate its detection and registration hospital-wide $[3,4,13,21,23$ $25,29,30,50,58,59,63,66-68,74,79,80,83,86]$. Among these a few research groups tried to develop the 'one algorithm to find them all' $[3,4,21,23,24,29,30]$, i.e. one algorithm that can be used to detect all types of $\mathrm{HAl}$ in all departments and medical specialties. The studies that aimed to achieve this, present sensitivities ranging from 0.78 to 0.99 . Du et al. [3] describe an excellently performing algorithm (sensitivity 0.99, specificity 0.93) to detect HAl in real time. Interestingly, they presented a decision support system to aid the ICP professional in making the final 'HAl present or not'decision. Doing so, they claim to have increased the overall specificity of their surveillance system to 0.99 . A downside to their approach was a decrease of sensitivity to 0.94 . This was due to the fact that the information provided by the support software was sometimes not sufficient for final confirmation of the presence of a $\mathrm{HAl}$ or no $\mathrm{HAl}$.
Algorithms and parameters used in electronically assisted surveillance system In their review 'Surveillance and use of computers in hospital infection control' Wenzel and Streed [87] presented a timeline of the evolution of surveillance of infectious diseases including healthcare-associated ones, from 1532 to 1989 , pointing out key figures and events in its history. As they elaborated on the different elements of surveillance, the authors eventually addressed how the application of computers could help infection control with their surveillance activities and add to their accuracy and probably to efficiency as well. In 2002 Peterson and Brossette [88] addressed the importance of clinical microbiological laboratories and the clinical microbiologist in HAI control. They stated that laboratory-based surveillance has the advantage of measuring hospital-wide occurrences from a single, central data collection point. These microbiological data could be used in a hospitalwide EASS of HAI. In 2008, Leal et al. [89] reviewed 24 articles in which microbiological data constituted the predominant variable used in electronic surveillance systems for HAl. Among those reviewed by Leal et al., six studies reported that $\mathrm{HAl}$ could be detected using microbiology data alone with reasonable to good overall sensitivity (range: 0.63-0.91) and excellent specificity (range: 0.87 to>0.99). According to the Leal et al. review, seven studies using only administrative data including discharge coding (International Classification of Diseases (ICD), 9th edition, Clinical Modification) and pharmacy data reported good sensitivity (range: 0.59-0.96) and excellent specificity (range: 0.95 to > 0.99) in detecting HAl. Moreover, six studies using both laboratory and administrative data reported a higher sensitivity (range: 0.71-0.94) but lower specificity (range: 0.47 to > 0.99) compared with the use of either alone. In 2013, Freeman et al. [90] performed a systematic review in which they categorised the EASS in multisource (including microbiological data) $(n=37)$, multisource (excluding microbiological data) $(n=4)$ and single source systems $(n=3)$. Of these 44 articles included for review, 21 were validation studies. There was no difference in the performance of multisource systems excluding or including microbiology. Of note, the single source validation studies, used natural language processing techniques to extract information from the radiology reports and electronic health record to detect LRTI and BSI respectively [33,91]. Based on the results of their review in 2014 de Bruin et al. [92] concluded that driven by the increased availability of electronic patient data, EASS tend to use more data sources. This is making systems more sensitive yet less specific, but also allows systems to be tailored to the needs of healthcare institutes' surveillance programmes. The findings of Cato's review [93], in 2015, suggest that the majority of EASS for HAI surveillance are using standard definitions of $\mathrm{HAl}$, but the lack of standardised use of data formats, denominator, and external validation in these systems reduces the reliability of their findings. 


\section{FIGURE 3}

Sensitivity of electronically assisted surveillance systems by category of algorithm used and by type of healthcare-associated infection $(\mathrm{n}=78)$

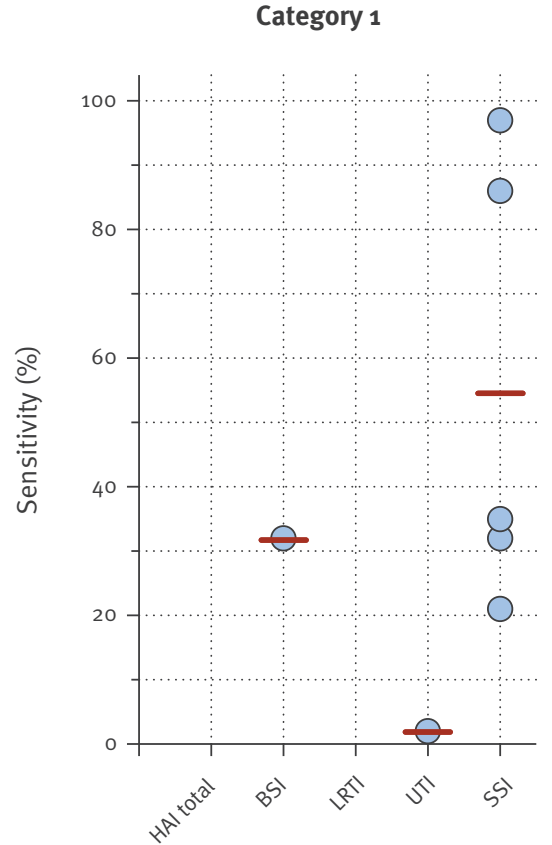

Type of HAI
Category 2

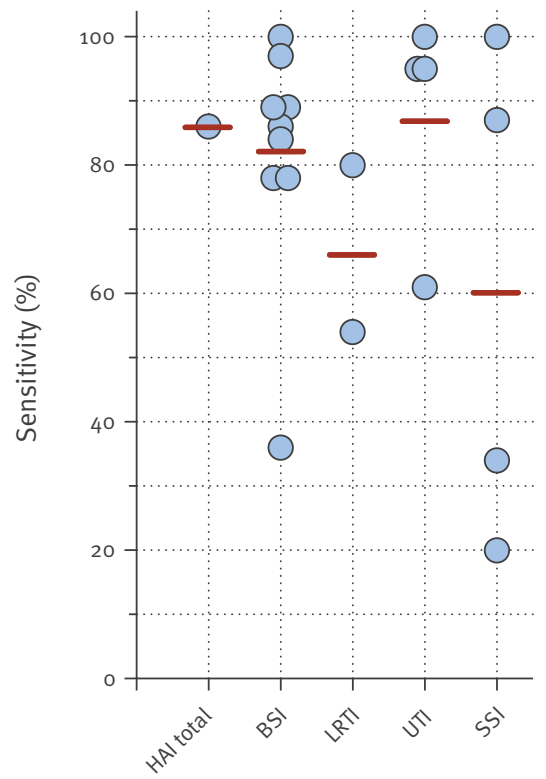

Type of HAl
Category 3

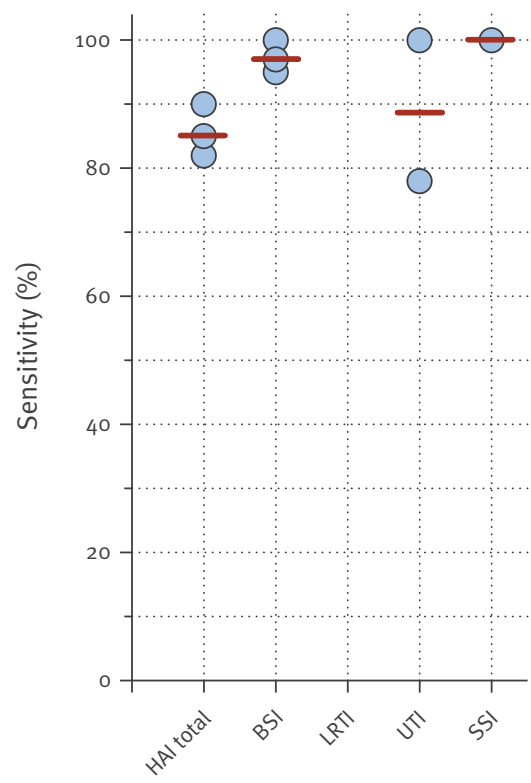

Type of HAI
Category 4

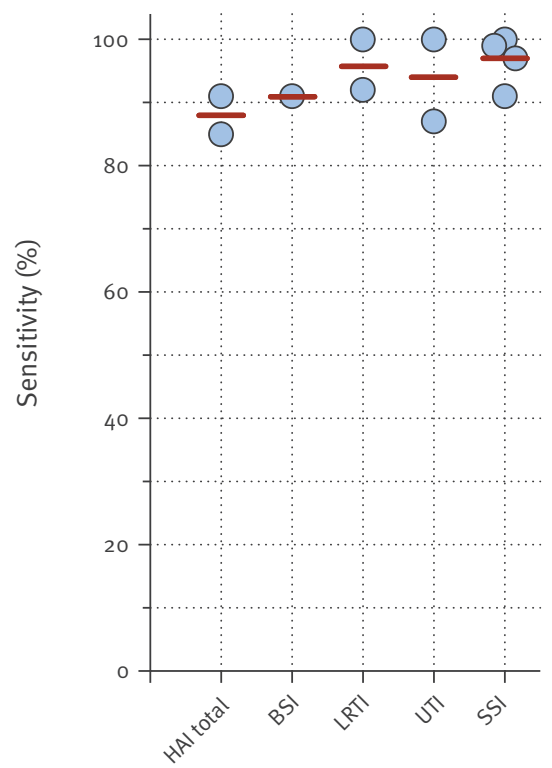

Type of HAI
Category 5

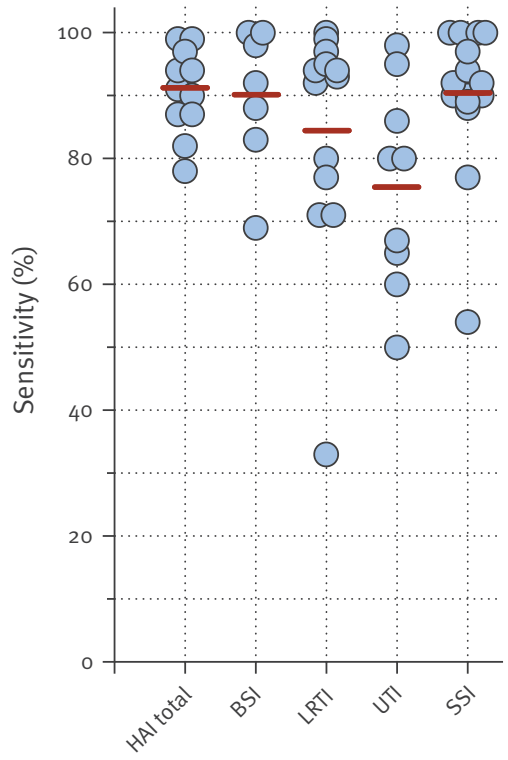

Type of HAl

BSI: bloodstream infections; HAI: healthcare-associated infection; LRTI: lower respiratory tract infections; SSI: surgical site infections; UTI: urinary tract infections.

Category 1: international classification of diseases coding only; category 2: microbiology (bacterial, viral, fungal pathogens detected by culture, molecular or serological diagnostics); category 3: microbiology + antibiotic prescriptions; category 4: microbiology + antibiotic prescriptions + clinical chemistry; category 5: other types of algorithms (using parameters like body temperature OR/AND judgement by physician OR/AND ventilator setting OR/AND fuzzy logic or natural language processing of clinical notes OR/AND risk factors, like indwelling catheters). The dots represent the sensitivities for each individual study per type of HAl, the red lines represent the average sensitivities. 


\section{Microbiological data}

The most prevalent variable included in EASS is the microbiological examination (present in at least one of the algorithms presented in 61 of the 78 articles). It is a crucial variable in algorithms for surveillance of BSI. Good sensitivities have been achieved using the results of microbiological examinations as the sole variable (Figure 3). In other types of HAI (UTI, SSI and LRTI) the sensitivity of algorithms that use microbiological examination alone is lower. As a consequence of the definitions used as 'gold standard', the microbiological examination variable is often combined with clinical characteristics (Figure 3). Although the microbiology variable seems straightforward, it can mean several things, i.e. the presence of bacteriological examinations, which use either culture, serological or molecular techniques or all of these. The presence and quality of the microbiological examination highly depends on the availability of the service - often lacking in low income settings -, and on the adherence to diagnostic protocols. Finally, a negative microbiological examination does not unequivocally exclude the presence an infectious disease.

\section{Chemistry}

Clinical chemistry evaluation of biomarkers for infections are routinely performed in most clinical settings. Leukocyte counts and C-reactive protein (CRP) are the variables of choice in different algorithms made for $\mathrm{HAl}$ surveillance, but they are always, in all 19 of 78 studies that use this variable, used in combination with other parameters $[3,26,35,36,39,42,43,45,46,49,56,64,65,7$ $0,72,73,75,82,87]$.

\section{Antibiotics}

Following microbiological data, antibiotic prescriptions data are the second most used variable in EASS algorithms (38 of 78 studies) and, when not combined with microbiological data, most often found in combination with ICD coding $[12,16,36,56]$.

\section{International Classification of Diseases}

The sensitivity of ICD-coding (9th or 10th edition) is generally low, in five of the seven studies that use this as the sole variable of the algorithm $[11,39,54,70,77,78,83]$. The two studies with sensitivities of 0.86 and 0.97 focused on SSI after coronary artery bypass graft surgery and total joint replacement $[39,54]$. ICD-coding has not been studied for all types of HAI surveillance nor for LRTI surveillance (Figure 2). Electronically assisted surveillance system per type of healthcare-associated infection

\section{Bloodstream infections (including central line associated)}

Twenty-three publications (Table 3) described the performance of an EASS to detect BSI. Sensitivity ranged from 0.32 to 1.0 , specificity from 0.37 to 1 .

In 2017, Gubbels et al. presented the results of an automated nationwide survey, using the Danish
Microbiology Database and the Danish National Patient Registry. National trends showed an increase in hospital-acquired bacteraemia (HAIBA) cases between 2010 and 2014. Although comparison of their HAIBA algorithm with the results of point prevalence surveys showed a sensitivity of 0.36 they concluded that given the many advantages of automated surveillance, the HAIBA algorithm allows monitoring of HAIBA across the healthcare system, supports prioritising preventive measures, and holds promise for evaluating interventions [80]. Another approach to automated surveillance of BSI is the reuse of the ICD-coding system. Unfortunately the performance to detect BSI in the paediatric ICU was shown to be very poor (sensitivity of 0.32), as Bond et al. showed [78]. In contrast, one adult ICU-tailored algorithm showed excellent performance characteristics (sensitivity and specificity of 1) [28]. The study was conducted at the 14-bed medical ICU (MICU) and the 22-bed surgical ICU (SICU) of Ghent University Hospital (1,050 beds), where Computer-based Surveillance and Alerting of infections Antimicrobial Resistance and Antibiotic consumption (COSARA) software has been available since 2010. With COSARA, all infection-related data from the various electronic patient records are integrated and presented to the treating ICU physician by means of a continuously updated clinical dash-board. This includes a graphical display of current and past antibiotic treatments as a timeline, and provides direct links to a real-time copy of the various source records. The graphical interface allows episodes of antibiotic treatment to be labelled according to a predefined list of indications and diagnoses, and linked with microbiological culture results [28]. Surveillance for CLABSIs by infection control practitioners is often limited to ICUs. Woeltje et al. applied an automated surveillance system for CLABSI outside the ICU. Is this study they evaluated the performance of 12 different rule sets for the detection of CLABSI. The best-performing rule set had an overall sensitivity of 0.95 , specificity of 0.97 , positive predictive value of 0.90 , and negative predictive value of 0.99 compared with intensive manual surveillance. The method offered the possibility of performing acceptably good surveillance in areas where resources do not allow for traditional manual surveillance [76]. This hospital-wide approach generally results in lower sensitivities $[4,13,63]$. However, Tseng et al. showed their hospital-wide EASS system performed very well in a 2,200-bed teaching hospital, with regard to sensitivity (0.98), specificity (0.99), positive predictive value (0.96), and negative predictive value (1) compared with their reference standard, which, remarkably, was a continuous manual, hospital-wide surveillance for BSI, including CLABSI, operating since 1981 [67].

Lower respiratory tract infections (including ventilatorassociated pneumonia)

Sixteen publications (Table 4) from 2005 to 2018 presented the performance of an EASS to detect LRTIs, including hospital-acquired pneumonia (HAP), mostly VAP. Sensitivity ranged from 0.33 to 1.0 and specificity 
TABLE 3

Performance characteristics of electronically assisted surveillance systems for surveillance of bloodstream infection (including central line associated infection) ( $\mathrm{n}=23$ studies)

\begin{tabular}{|c|c|c|c|c|c|c|c|c|c|}
\hline Ref. & First author & Algorithm category & $\begin{array}{c}\text { Year of } \\
\text { publication }\end{array}$ & Sensitivity & Specificity & PPV & NPV & Accuracy ${ }^{\mathrm{a}}$ & Concordance \\
\hline [68] & Tseng & Other & 2013 & NA & NA & NA & NA & 0.94 & NA \\
\hline [82] & Leal & Microbiology & 2016 & NA & NA & NA & NA & NA & 0.97 \\
\hline [18] & Bouzbid & Other & 2011 & 1 & 0.37 & 0.1 & 1 & NA & NA \\
\hline [28] & De Bus & Other & 2014 & 1 & 1 & NA & NA & NA & NA \\
\hline [58] & Redder & $\begin{array}{l}\text { Microbiology } \\
+ \text { antibiotics }\end{array}$ & 2015 & 1 & 1 & 0.88 & 1 & NA & NA \\
\hline [73] & Venable & Microbiology & 2013 & 1 & 0.92 & NA & NA & NA & NA \\
\hline [67] & Tseng & Other & 2015 & 0.98 & 0.99 & 0.96 & 1 & NA & NA \\
\hline [75] & Woeltje & $\begin{array}{l}\text { Microbiology } \\
\text { + antibiotics }\end{array}$ & 2008 & 0.97 & 0.44 & 0.15 & 0.99 & NA & NA \\
\hline [66] & Trick & Microbiology & 2004 & 0.97 & 0.73 & NA & NA & NA & NA \\
\hline [76] & Woeltje & $\begin{array}{l}\text { Microbiology } \\
+ \text { antibiotics }\end{array}$ & 2011 & 0.95 & 0.98 & 0.9 & 0.99 & NA & NA \\
\hline [40] & Kaiser & Other & 2014 & 0.92 & 1 & 1 & 1 & NA & NA \\
\hline [63] & Streefkerk & $\begin{array}{l}\text { Microbiology } \\
\text { + antibiotics } \\
\text { + chemistry }\end{array}$ & 2014 & 0.91 & NA & NA & NA & NA & NA \\
\hline [59] & Ridgway & Microbiology & 2016 & 0.89 & 1 & NA & 1 & NA & NA \\
\hline [17] & Bouam & Microbiology & 2003 & 0.89 & 0.75 & 0.63 & 0.93 & NA & NA \\
\hline [35] & Henry & Other & 2013 & 0.88 & 0.92 & NA & NA & NA & NA \\
\hline [4] & Brossette & Microbiology & 2006 & 0.86 & 1 & NA & NA & NA & NA \\
\hline [32] & Graham & Microbiology & 2004 & 0,84 & 0.99 & 0.84 & 0.99 & NA & NA \\
\hline [86] & Streefkerk & $\begin{array}{l}\text { Microbiology } \\
\text { + antibiotics } \\
\text { + chemistry }\end{array}$ & 2016 & 0.83 & NA & NA & NA & NA & NA \\
\hline [14] & Bellini & Microbiology & 2007 & 0.78 & 0.93 & NA & NA & NA & NA \\
\hline [61] & Stamm & Microbiology & 2012 & 0.78 & NA & 0.5 & NA & NA & NA \\
\hline [13] & Bearman & Other & 2010 & 0.69 & 0.88 & 0.05 & NA & NA & NA \\
\hline [80] & Gubbels & Microbiology & 2017 & 0.36 & 0.99 & NA & NA & NA & NA \\
\hline [78] & Bond & ICD codes & 2016 & 0.32 & NA & NA & NA & NA & NA \\
\hline
\end{tabular}

ICD: International Classification of Diseases; HAI: healthcare-associated infection; NA: data not available; NPV: negative predictive value; PPV: positive predictive value; ref.: reference.

a Accuracy is calculated as: $(T P+T N) /(T P+T N+F P+F N)$ where TP is the true positive (i.e. the number of individuals correctly identified as positive for a given $\mathrm{HAI}$ ), $\mathrm{FP}$ is the false positive (i.e. the number of individuals incorrectly identified as positive for the given $\mathrm{HAl}$ ), TN is the true negative (i.e. the number of individuals correctly identified as negative for the given $\mathrm{HAI}$ ) and FN is the false negative (i.e. the number of individuals incorrectly identified as negative for the given $\mathrm{HAl}$ ).

from 0.58 to 1.0 . The majority of the studies $(14 / 16)$ addressed the performance of an EASS to detect VAP in an ICU setting, including two neonatal ICUs. Because of the complexity of the definitions, ventilator-associated events (VAE), ventilator-associated conditions (VAC) or VAP, comparing the studies' methods and results is difficult.

Urinary tract infections (including catheter-associated urinary tract infections)

UTI is one of the 'big four' and is third, behind SSI and LRTI, in HAI prevalence in the Netherlands (2017) [94].
Internationally 18 publications (Table 5) presented the performance of an EASS to detect catheter-associated (CA)UTI. Reported sensitivities ranged from 0.02 to 1.0 , whereas specificities ranged from 0.59 to 1.0. There are several reasons for the low sensitivity described in the report by Condell et al., including laboratory results being unavailable at the time of the survey, the results considered clinically irrelevant by the surveyor due to an indwelling urinary catheter or lack of clinical signs of infection. UTIs being considered hospital-acquired in 'the gold standard' even though the first sample was taken within 48 hours of admission also compromised 
Performance characteristics of electronically assisted surveillance systems for surveillance of lower respiratory tract infection (including ventilator associated infection) ( $\mathrm{n}=16$ studies)

\begin{tabular}{|c|c|c|c|c|c|c|c|}
\hline Ref. & First author & Algorithm category & Year of publication & Sensitivity & Specificity & PPV & NPV \\
\hline [51] & Mann & Other & 2015 & 1 & 1 & 1 & 1 \\
\hline [81] & Hebert & $\begin{array}{l}\text { Microbiology } \\
+ \text { antibiotics } \\
+ \text { chemistry }\end{array}$ & 2018 & 1 & NA & NA & NA \\
\hline [18] & Bouzbid & Other & 2011 & 0.99 & 0.58 & 0.22 & 1 \\
\hline [26] & Claridge & Other & 2009 & 0.97 & 1 & NA & NA \\
\hline [42] & Klompas & Other & 2008 & 0.95 & 1 & NA & NA \\
\hline [86] & Streefkerk & $\begin{array}{l}\text { Microbiology } \\
+ \text { antibiotics } \\
\text { + chemistry }\end{array}$ & 2016 & 0.94 & NA & NA & NA \\
\hline [62] & Stevens & Other & 2014 & 0.94 & NA & 1 & $\mathrm{NA}$ \\
\hline [55] & Nuckchady & Other & 2015 & 0.93 & 0.99 & 0.95 & 0.98 \\
\hline [40] & Kaiser & Other & 2014 & 0.92 & 1 & 1 & 1 \\
\hline [63] & Streefkerk & $\begin{array}{l}\text { Microbiology } \\
+ \text { antibiotics } \\
\text { + chemistry }\end{array}$ & 2014 & 0.92 & NA & NA & NA \\
\hline [35] & FitzHenry & Other & 2013 & 0.8 & 0.9 & NA & NA \\
\hline [28] & De Bus & Other & 2014 & 0.77 & 0.99 & NA & NA \\
\hline [33] & Haas & Other & 2005 & 0.71 & 0.95 & 0.08 & 1 \\
\hline [52] & Mendonca & Other & 2005 & 0.71 & 0.99 & 0.075 & NA \\
\hline [61] & Stamm & Microbiology & 2012 & 0.54 & NA & 0.25 & NA \\
\hline [43] & Klouwenberg & Other & 2014 & 0.33 & NA & 0.25 & NA \\
\hline
\end{tabular}

NA: data not available; NPV: negative predictive value; PPV: positive predictive value; ref.: reference.

sensitivity [79]. ICD-10 codes for UTI surveillance were shown to perform poorly (sensitivity 0.02) and were only studied in one study [83]. On the other hand a urine culture as the only parameter proved to perform well $[38,50]$.

\section{Surgical site infections}

Not surprisingly, the majority of publications, 29 in total, presented the performance of an EASS to detect SSI (Table 6). Different fields of surgery are targeted, from neurosurgery to total hip replacements and different algorithms with sensitivities ranging from 0.02 to 1.0 and specificities ranging from 0.59 to 1.0 have been explored. Administrative data (ICD-9 admission and discharge coding and claims data) generally performed poorly when used as the only variable for case finding $[37,46,54,70,77]$.

Interestingly a Michigan study by Baker et al. showed a 0.89 sensitivity for ICD-9 codes when these were solely used to determine post-caesarean section SSIs. Combining ICD-9 with specific post-operative antibiotics increased the specificity of the case finding algorithm to 0.95 and resulted in a ca $90 \%$ workload reduction [12]. Fifteen years later in Denmark, comparable performance characteristics were found for in-hospital and post-discharge surveillance of postcaesarean section SSIs using ICD-10 discharge codes in combination with relevant antibiotics and culture data [49].

Adding microbiology and radiographic data (culture, magnetic resonance imaging ordered) as variables of case finding algorithms resulted in a positive predictive value of 0.97 , although at the cost of sensitivity (0.48) [19]. A text mining algorithm as presented by Michelson et al. found all of the 22 SSIs detected by traditional hospital-based surveillance, along with an additional 37 SSIs not detected by traditional surveillance [53].

\section{Quality and performance}

The quality of the 78 studies included in this review varied from an overall quality score of 5 to 26 . Likewise, the overall performance score of the EASS developed and used for HAl surveillance varied widely among the studies, with overall performance scores ranging from a low 0.2 to the maximum of 1.0. When quality of study design was plotted against the level of performance of the EASS there seemed to be a, albeit weak, negative 
Performance characteristics of electronically assisted surveillance systems for surveillance of urinary tract infection (including catheter-associated infection) ( $\mathrm{n}=18$ studies)

\begin{tabular}{|c|c|c|c|c|c|c|c|}
\hline Ref. & First author & Algorithm category & Year of publication & Sensitivity & Specificity & PPV & NPV \\
\hline [50] & Lo & $\begin{array}{l}\text { Microbiology } \\
+ \text { antibiotics }\end{array}$ & 2013 & 1 & 0.95 & NA & NA \\
\hline [38] & Hsu & $\begin{array}{l}\text { Microbiology } \\
\text { + antibiotics } \\
\text { + chemistry }\end{array}$ & 2015 & 1 & 1 & NA & NA \\
\hline [73] & Venable & Microbiology & 2013 & 1 & 0.97 & NA & NA \\
\hline [18] & Bouzbid & Other & 2011 & 0.98 & 0.59 & 0.183 & 1 \\
\hline [17] & Bouam & Microbiology & 2003 & 0.95 & 1 & 1 & 0.95 \\
\hline [4] & Brossette & Microbiology & 2006 & 0.95 & 1 & NA & NA \\
\hline [35] & Henry & Other & 2013 & 0.95 & 0.8 & $\mathrm{NA}$ & NA \\
\hline [63] & Streefkerk & $\begin{array}{l}\text { Microbiology } \\
+ \text { antibiotics } \\
\text { + chemistry }\end{array}$ & 2014 & 0.87 & NA & NA & NA \\
\hline [25] & Choudhuri & Other & 2011 & 0.86 & 0.94 & 0.85 & 0.94 \\
\hline [28] & De Bus & Other & 2014 & 0.8 & 0.99 & NA & NA \\
\hline [74] & Wald & Other & 2014 & 0.8 & 0.99 & 0.69 & 0.99 \\
\hline [58] & Redder & $\begin{array}{l}\text { Microbiology } \\
+ \text { antibiotics }\end{array}$ & 2015 & 0.78 & 0.93 & 0.88 & 0.87 \\
\hline [86] & Streefkerk & $\begin{array}{l}\text { Microbiology } \\
\text { + antibiotics } \\
\text { + chemistry }\end{array}$ & 2016 & 0.67 & NA & NA & NA \\
\hline [20] & Branch-Elliman & Other & 2015 & 0.65 & 1 & 0.54 & 1 \\
\hline [62] & Stamm & Microbiology & 2012 & 0.61 & NA & 0.47 & NA \\
\hline [65] & Tanushi & Other & 2014 & 0.6 & 0.99 & NA & 0.98 \\
\hline [79] & Condell & Other & 2016 & 0.5 & 0.94 & NA & NA \\
\hline [83] & Marra & ICD codes & 2017 & 0.02 & NA & $\mathrm{NA}$ & $\mathrm{NA}$ \\
\hline
\end{tabular}

ICD: International Classification of Diseases; NA: data not available; NPV: negative predictive value; PPV: positive predictive value; ref.: reference.

correlation, suggesting that the best designed studies tended to yield lower performance scores or vice versa, that the studies reporting very high performance scores of their EASS were generally less well designed (Figure 4).

Based on this view of the overall quality and performance score we selected the 10 best studies (labelled in the figure) that showed the highest overall quality scores and also yielded a high overall performance score $\geq 0.85$ (Figure 4 upper right quadrant). They, together, constitute a reference or can be considered a benchmark, for EASS development. Interestingly all these studies were reported only recently (20132016), indicating that some progress has been made in designing and evaluating EASS (Table 7).

Interestingly, the majority of the 10 best EASS presented in Table 7 used a two-step procedure, first a selection step based on an automated algorithm, followed by step in which a confirmatory assessment of the selected cases by the ICP is performed. The monitoring of nosocomial infections (MONI) software on the ICU, the MONI-ICU system [27], however, achieved a high specificity of the EASS for all types of HAl based on an automated selection step only. This was achieved in a university hospital ICU by building a system consisting of fuzzy logic sets, which used a rich dataset including clinical, laboratory and nursing data from the patient data management systems in operation at the ICU wards on a daily basis. Du et al. [3] showed that based on a dataset including microbiology, clinical chemistry, antibiotics prescriptions and clinical characteristics, it is possible to perform continuous hospital-wide all type HAl surveillance with an EASS. Of note, they stated that their hospital has the most advanced computer information system in China, including an integrated hospital information system (IHIS). When documented in the electronic patient record clinical characteristics, like body temperature or 
TABLE 6

Performance characteristics of electronically assisted surveillance systems for surveillance of surgical site infection $(\mathrm{n}=29$ studies)

\begin{tabular}{|c|c|c|c|c|c|c|c|c|}
\hline Ref. & First author & Algorithm category & Year of publication & Sensitivity & Specificity & PPV & NPV & Accuracy \\
\hline [11] & Apte & ICD codes & 2011 & 0.86 & NA & NA & NA & NA \\
\hline [12] & Baker & Other & 1995 & 0.89 & 0.95 & 0.53 & $\mathrm{NA}$ & NA \\
\hline [16] & Bolon & Other & 2009 & 1 & NA & 0.07 & 1 & NA \\
\hline [19] & Branch-Elliman & Other & 2014 & 0.97 & 0.98 & NA & NA & NA \\
\hline [4] & Brossette & Microbiology & 2006 & 1 & 0.6 & NA & NA & NA \\
\hline [23] & Chalfine & Microbiology & 2005 & 0.84 & 1 & NA & NA & NA \\
\hline [31] & Gerbier-Colomban & Other & 2012 & 0.92 & 0.86 & NA & NA & NA \\
\hline [34] & Hautemanière & Other & 2013 & 0.54 & 0.95 & 0.74 & 0.88 & NA \\
\hline [35] & Henry & Other & 2013 & 0.77 & 0.63 & NA & NA & NA \\
\hline [37] & Hollenbeak & Microbiology & 2011 & 0.2 & 0.96 & NA & NA & 0.89 \\
\hline [39] & Inacio & ICD codes & 2011 & 0.97 & 0.92 & NA & $\mathrm{NA}$ & NA \\
\hline [41] & King & Other & 2014 & 0.9 & 0.94 & NA & NA & NA \\
\hline [44] & Knepper & Other & 2013 & 1 & 0.88 & NA & $\mathrm{NA}$ & NA \\
\hline [45] & Knepper & Other & 2014 & 0.94 & 0.88 & NA & NA & NA \\
\hline [46] & Kulaylat & Microbiology & 2016 & 0.37 & 1 & 0.72 & 0.99 & NA \\
\hline [47] & Leclere & Other & 2014 & 0.90 & 0.98 & 0.25 & 1 & NA \\
\hline [49] & Leth & Other & 2010 & 0.90 & 0.98 & 0.54 & 1 & NA \\
\hline [53] & Michelson & Other & 2014 & 1 & NA & NA & NA & NA \\
\hline [54] & Moro & ICD codes & 2004 & 0.21 & NA & NA & NA & NA \\
\hline [63] & Streefkerk & $\begin{array}{l}\text { Microbiology } \\
\text { + antibiotics } \\
\text { + chemistry }\end{array}$ & 2014 & 0.91 & NA & NA & NA & NA \\
\hline [69] & van Mourik & $\begin{array}{l}\text { Microbiology } \\
+ \text { antibiotics } \\
\text { + chemistry }\end{array}$ & 2011 & 0.99 & 0.88 & 0.57 & 1 & NA \\
\hline [70] & van Mourik & ICD codes & 2013 & 0.32 & NA & 0.35 & NA & NA \\
\hline [71] & van Mourik & $\begin{array}{l}\text { Microbiology } \\
+ \text { antibiotics } \\
\text { + chemistry }\end{array}$ & 2012 & 1 & NA & 0.59 & NA & NA \\
\hline [72] & van Mourik & $\begin{array}{l}\text { Microbiology } \\
+ \text { antibiotics } \\
\text { + chemistry }\end{array}$ & 2015 & 0.97 & NA & 0.47 & NA & NA \\
\hline [77] & $\mathrm{Yu}$ & ICD codes & 2014 & 0.35 & 0.97 & 0.19 & 0.99 & NA \\
\hline [56] & Perdiz & Other & 2016 & 0.88 & 1 & 1 & 1 & NA \\
\hline [86] & Streefkerk & $\begin{array}{l}\text { Microbiology } \\
+ \text { antibiotics } \\
\text { + chemistry }\end{array}$ & 2016 & 1 & NA & NA & NA & NA \\
\hline [84] & Pindijck & Other & 2018 & 0.92 & 0.57 & NA & NA & NA \\
\hline [85] & Sips & $\begin{array}{l}\text { Microbiology } \\
+ \text { antibiotics } \\
\end{array}$ & 2017 & 1 & NA & 0.68 & NA & NA \\
\hline
\end{tabular}

ICD: International Classification of Diseases; NA: data not available; NPV: negative predictive value; PPV: positive predictive value; ref.: reference. 


\section{FIGURE 4}

Distribution of overall quality score of studies on electronically assisted surveillance systems vs the overall performance score of the electronically assisted surveillance system reported in these studies $(n=78)$

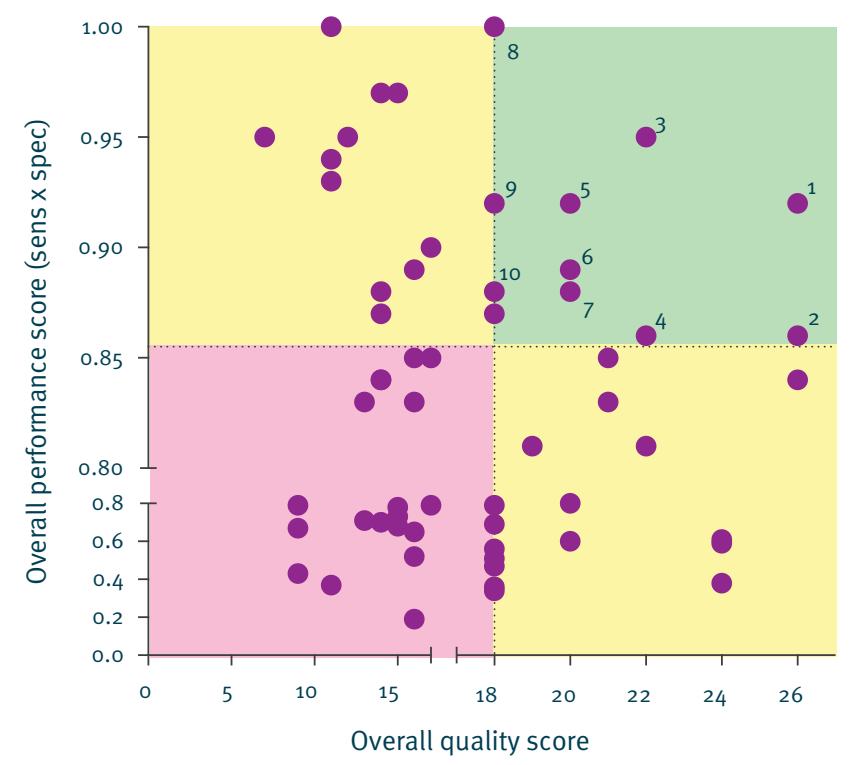

Sens: sensitivity; spec: specificity.

In the upper right quadrant the 10 best studies are ranked from 1 to 10 (see Table 7 for more detail).

the presence of invasive devices, improve sensitivity and specificity of EASS. The data in Table 7 suggests that richer datasets lead to better performing EASS. Remarkably only five articles presented the time reduction achieved by using an EASS.

\section{Conclusions}

Ideally, surveillance of HAls comprises all departments, medical specialties and includes all types of $\mathrm{HAl}$, because only then fully informed decisions can be made to prioritise and structurally address the relevant infection issues of the particular healthcare setting. In this review of the literature we found that very few EASS are 'all types, hospital-wide', although performance characteristics of these systems are generally good. The absence of traditional hospital-wide surveillance of $\mathrm{HAl}$ by the infection preventionist, which can be used as gold standard for validation can be one cause. On the other hand, the fact that most studies have been performed in an ICU setting implicates that hospital-wide electronic health records or data warehouses are still not ready to be used for decision support and surveillance.

Because of limited resources and the labour intensity of manual surveillance systems, efforts have been made to improve the efficiency of $\mathrm{HAl}$ surveillance by applying information technologies to query electronic datasets. However, we found that in literature, less than $20 \%$ of the studies present the actual time reduction that was achieved by introducing an EASS for HAl. Oher quality indicators, most importantly using different populations for development, testing and validation, are also lacking. Although sensitivity of EASS is generally high the specificity is variable, needing a confirmatory computer-assisted assessment by the infection preventionist and decision support. The parameters used in the algorithms studied vary considerably, do not have a standardised format nor are readily available in all hospital settings around the globe.

Although PRISMA guidelines were followed, this review has some limitations. Only English literature and no grey literature were considered for inclusion. The scoring system that was developed for and used in this study to assess the quality of the included studies' design was not prior validated.

In summary, thus far computer-assisted surveillance of $\mathrm{HAl}$ has not reached a mature stage, it is yet to be used routinely in most healthcare settings; we are learning, but we have not yet mastered the art. Although progress is being made towards a digital infrastructure for the learning health system [95], it is, in our opinion, not likely that EASS of HAI will be implemented globally within the next decade. A data-driven and decisionsupported healthcare system, including infection control surveillance, requires next generation electronic health records systems [96], clinical ownership and a good and close working relationship between infection control professionals and medical information specialists [97].

We recommend that future studies on the development and implementation of EASS of HAl focus on thorough validation, reproducibility in different hospital-settings of the algorithm and standardised datasets and present detailed information on efficiency. This information, together with the continuous focus on the importance of surveillance of $\mathrm{HAl}$, is needed to convince healthcare providers, professionals and boards of directors, to invest in EASS, in the future of infection control.

\section{Conflict of interest}

None declared.

\section{Authors' contributions}

HS and WB performed the online database query. HV and HS read all abstract and selected studies for full text review. HS wrote manuscript. RV created the figures and RV and HV supervised the review.

\section{References}

1. Zingg W, Holmes A, Dettenkofer M, Goetting T, Secci F, Clack $L$, et al. systematic review and evidence-based guidance on organization of hospital infection control programmes (SIGHT) study group. Hospital organisation, management, and structure for prevention of health-care-associated infection: a systematic review and expert consensus. Lancet 


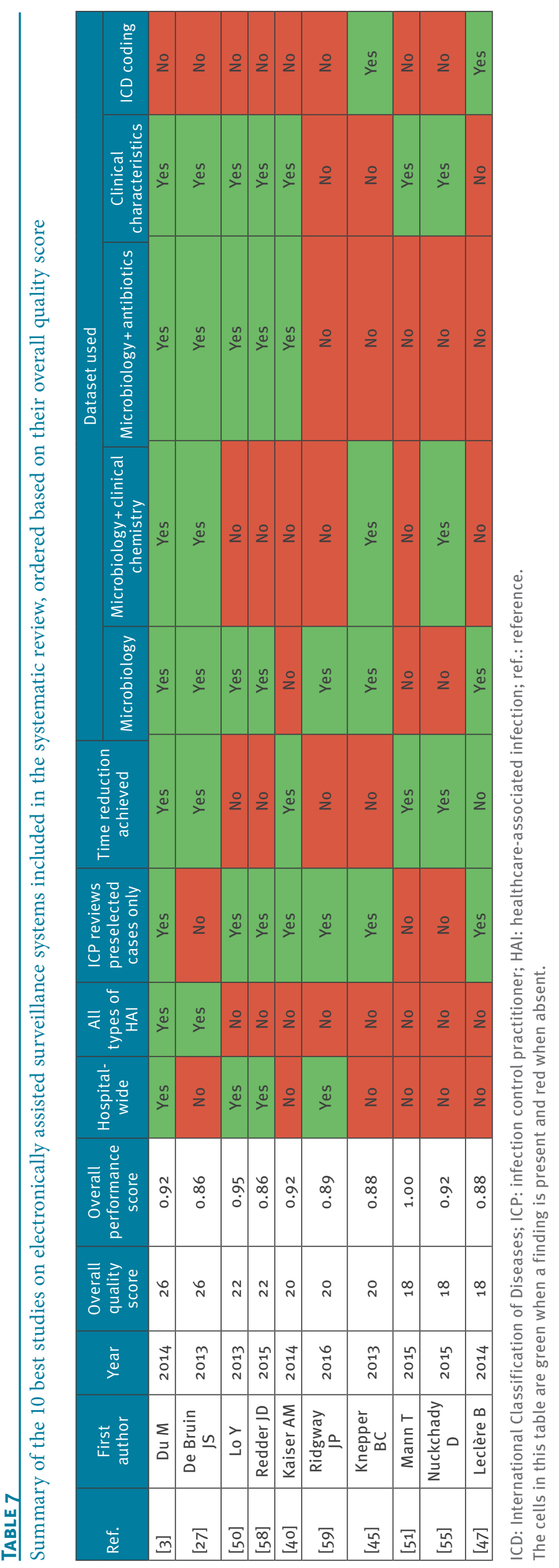


Infect Dis. 2015;15(2):212-24. https://doi.org/10.1016/S14733099(14)70854-0 PMID: 25467650

2. Storr J, Twyman A, Zingg W, Damani N, Kilpatrick C, Reilly J, et al. WHO Guidelines Development Group. Core components for effective infection prevention and control programmes: new WHO evidence-based recommendations. Antimicrob Resist Infect Control. 2017;6(1):6. https://doi.org/10.1186/s13756016-0149-9 PMID: 28078082

3. Du M, Xing Y, Suo J, Liu B, Jia N, Huo R, et al. Real-time automatic hospital-wide surveillance of nosocomial infections and outbreaks in a large Chinese tertiary hospital. BMC Med Inform Decis Mak. 2014;14(1):9. https://doi.org/10.1186/14726947-14-9 PMID: 24475790

4. Brossette SE, Hacek DM, Gavin PJ, Kamdar MA, Gadbois KD, Fisher AG, et al. A laboratory-based, hospital-wide, electronic marker for nosocomial infection: the future of infection control surveillance? Am J Clin Pathol. 2006;125(1):34-9. https://doi. org/10.1309/502AUPR8VE67MBDE PMID: 16482989

5. Liberati A, Altman DG, Tetzlaff J, Mulrow C, Gøtzsche PC, Ioannidis JP, et al. The PRISMA statement for reporting systematic reviews and meta-analyses of studies that evaluate healthcare interventions: explanation and elaboration. BMJ. 2009;339(jul21 1):b2700. https://doi.org/10.1136/bmj.b270o PMID: 19622552

6. Bramer WM, de Jonge GB, Rethlefsen ML, Mast F, Kleijnen J. A systematic approach to searching: an efficient and complete method to develop literature searches. J Med Libr Assoc. 2018;106(4):531-41. https://doi.org/10.5195/JMLA.2018.283 PMID: 30271302

7. Bramer WM, Rethlefsen ML, Mast F, Kleijnen J. Evaluation of a new method for librarian-mediated literature searches for systematic reviews. Res Synth Methods. 2018;9(4):510-20. https://doi.org/10.1002/jrsm.1279 PMID: 29073718

8. Bramer WM. Reference checking for systematic reviews using Endnote. J Med Libr Assoc. 2018;106(4):542-6. https://doi. org/10.5195/JMLA.2018.489 PMID: 30271303

9. Centers for Disease Control and Prevention (CDC)/National Healthcare Safety Network (NHSN). Surveillance Definitions. Atlanta: CDC; January 2020. Available from: https://www.cdc. gov/nhsn/pdfs/pscmanual/pcsmanual_current.pdf

10. Govindan M, Van Citters AD, Nelson EC, Kelly-Cummings J, Suresh G. Automated detection of harm in healthcare with information technology: a systematic review. Qual Saf Health Care. 2010;19(5):e11. PMID: 20671081

11. Apte M, Landers T, Furuya Y, Hyman S, Larson E. Comparison of two computer algorithms to identify surgical site infections. Surg Infect (Larchmt). 2011;12(6):459-64. https://doi. org/10.1089/sur.2010.109 PMID: 22136489

12. Baker C, Luce J, Chenoweth C, Friedman C. Comparison of case-finding methodologies for endometritis after cesarean section. Am J Infect Control. 1995;23(1):27-33. https://doi. org/10.1016/0196-6553(95)90005-5 PMID: 7762871

13. Bearman GML, Oppenheim MI, Mendonca EA, Hupert N, Behta M, Christos PJ, et al. A Clinical Predictive Model for Cathete Related Bloodstream Infections from the Electronic Medical Record. Open Epidemiology.2010;3(1):24-8. https://doi.org/10. 2174/1874297101003010024

14. Bellini C, Petignat C, Francioli P, Wenger A, Bille J, Klopotov $A$, et al. Comparison of automated strategies for surveillance of nosocomial bacteremia. Infect Control Hosp Epidemiol. 2007;28(9):1030-5. https://doi.org/10.1086/519861 PMID: 17932822

15. Blacky A, Mandl H, Adlassnig KP, Koller W. Fully Automated Surveillance of Healthcare-Associated Infections with MONIICU: A Breakthrough in Clinical Infection Surveillance. Appl Clin Inform. 2011;2(3):365-72. https://doi.org/10.4338/ACI-201103-RA-0022 PMID: 23616883

16. Bolon MK, Hooper D, Stevenson KB, Greenbaum M, Olsen MA Herwaldt L, et al. Centers for Disease Control and Prevention Epicenters Program. Improved surveillance for surgical site infections after orthopedic implantation procedures: extending applications for automated data. Clin Infect Dis. 2009;48(9):1223-9. https://doi.org/10.1086/597584 PMID: 19335165

17. Bouam S, Girou E, Brun-Buisson C, Karadimas H, Lepage E. An intranet-based automated system for the surveillance of nosocomial infections: prospective validation compared with physicians' self-reports. Infect Control Hosp Epidemiol. 2003;24(1):51-5. https://doi.org/10.1086/502115 PMID: 12558236

18. Bouzbid S, Gicquel Q, Gerbier S, Chomarat M, Pradat E, Fabry J, et al. Automated detection of nosocomial infections: evaluation of different strategies in an intensive care unit 2000-2006. J Hosp Infect. 2011;79(1):38-43. https://doi.org/10.1016/j. jhin.2011.05.006 PMID: 21742413
19. Branch-Elliman W, Strymish J, Itani KM, Gupta K. Using clinical variables to guide surgical site infection detection: a novel surveillance strategy. Am J Infect Control. 2014;42(12):1291-5. https://doi.org/10.1016/j.ajic.2014.08.013 PMID: 25465259

20. Branch-Elliman W, Strymish J, Kudesia V, Rosen AK, Gupta K. Natural language processing for real-time catheterassociated urinary tract infection surveillance: Results of a pilot implementation trial. Infect Control Hosp Epidemiol. 2015;36(9):1004-10. https://doi.org/10.1017/ice.2015.122 PMID: 26022228

21. Broderick A, Mori M, Nettleman MD, Streed SA, Wenzel RP. Nosocomial infections: validation of surveillance and computer modeling to identify patients at risk. Am J Epidemiol. 1990;131(4):734-42. https://doi.org/10.1093/oxfordjournals. aje.a115558 PMID: 2180283

22. Brown C, Richards M, Galletly T, Coello R, Lawson W, Aylin $P$, et al. Use of anti-infective serial prevalence studies to identify and monitor hospital-acquired infection. J Hosp Infect. 2009;73(1):34-40. https://doi.org/10.1016/j.jhin.2009.05.020 PMID: 19647890

23. Chalfine A, Cauet D, Lin WC, Gonot J, Calvo-Verjat N, Dazza FE, et al. Highly sensitive and efficient computer-assisted system for routine surveillance for surgical site infection. Infect Control Hosp Epidemiol. 2006;27(8):794-801. https://doi. org/10.1086/506393 PMID: 16874638

24. Chang YJ, Yeh ML, Li YC, Hsu CY, Lin CC, Hsu MS, et al. Predicting hospital-acquired infections by scoring system with simple parameters. PLoS One. 2011;6(8):e23137. https://doi. org/10.1371/journal.pone.0023137 PMID: 21887234

25. Choudhuri JA, Pergamit RF, Chan JD, Schreuder AB, McNamara E, Lynch JB, et al. An electronic catheter-associated urinary tract infection surveillance tool. Infect Control Hosp Epidemiol. 2011;32(8):757-62. https://doi.org/10.1086/661103 PMID: 21768758

26. Claridge JA, Golob JF Jr, Fadlalla AM, D'Amico BM, Peerless JR, Yowler CJ, et al. Who is monitoring your infections: shouldn't you be? Surg Infect (Larchmt). 2009;10(1):59-64. https://doi. org/10.1089/sur.2008.056 PMID: 19250007

27. de Bruin JS, Adlassnig KP, Blacky A, Mandl H, Fehre K, Koller W. Effectiveness of an automated surveillance system for intensive care unit-acquired infections. J Am Med Inform Assoc. 2013;20(2):369-72. https://doi.org/10.1136/ amiajnl-2012-000898 PMID: 22871398

28. De Bus L, Diet G, Gadeyne B, Leroux-Roels I, Claeys G, Steurbaut K, et al. Validity analysis of a unique infection surveillance system in the intensive care unit by analysis of a data warehouse built through a workflow-integrated software application. J Hosp Infect. 2014;87(3):159-64. https://doi. org/10.1016/j.jhin.2014.03.010 PMID: 24856115

29. Evans RS, Burke JP, Classen DC, Gardner RM, Menlove RL, Goodrich KM, et al. Computerized identification of patients at high risk for hospital-acquired infection. Am J Infect Control. 1992;20(1):4-10. https://doi.org/10.1016/S01966553(05)80117-8 PMID: 1554148

30. Evans RS, Larsen RA, Burke JP, Gardner RM, Meier FA, Jacobson $J A$, et al. Computer surveillance of hospital-acquired infections and antibiotic use. JAMA. 1986;256(8):1007-11. https://doi. org/10.1001/jama.1986.03380080053027 PMID: 3735626

31. Gerbier-Colomban S, Bourjault M, Cêtre JC, Baulieux J, Metzger $\mathrm{MH}$. Evaluation study of different strategies for detecting surgical site infections using the hospital information system at Lyon University Hospital, France. Ann Surg. 2012;255(5):896 900. https://doi.org/10.1097/SLA.ob013e31824e6f4f PMID: 22415422

32. Graham PL 3rd, San Gabriel P, Lutwick S, Haas J, Saiman L. Validation of a multicenter computer-based surveillance system for hospital-acquired bloodstream infections in neonatal intensive care departments. Am J Infect Control. 2004;32(4):232-4. https://doi.org/10.1016/j.ajic.2003.07.008 PMID: 15175620

33. Haas JP, Mendonça EA, Ross B, Friedman C, Larson E. Use of computerized surveillance to detect nosocomial pneumonia in neonatal intensive care unit patients. Am J Infect Control. 2005;33(8):439-43. https://doi.org/10.1016/j.ajic.2005.06.008 PMID: 16216656

34. Hautemanière A, Florentin A, Hunter PR, Bresler L, Hartemann $P$. Screening for surgical nosocomial infections by crossing databases. J Infect Public Health. 2013;6(2):89-97. https://doi. org/10.1016/j.jiph.2012.08.002 PMID: 23537821

35. FitzHenry F, Murff HJ, Matheny ME, Gentry N, Fielstein EM, Brown SH, et al. Exploring the frontier of electronic health record surveillance: the case of postoperative complications. Med Care. 2013;51(6):509-16. https://doi.org/10.1097/ MLR.ob013e31828d1210 PMID: 23673394

36. Hirschhorn LR, Currier JS, Platt R. Electronic surveillance of antibiotic exposure and coded discharge diagnoses as 
indicators of postoperative infection and other quality assurance measures. Infect Control Hosp Epidemiol. 1993;14(1):21-8. https://doi.org/10.2307/30146509 PMID: 8432965

37. Hollenbeak CS, Boltz MM, Nikkel LE, Schaefer E, Ortenzi G, Dillon PW. Electronic measures of surgical site infection: implications for estimating risks and costs. Infect Control Hosp Epidemiol. 2011;32(8):784-90. https://doi. org/10.1086/660870 PMID: 21768762

38. Hsu HE, Shenoy ES, Kelbaugh D, Ware W, Lee H, Zakroysky P, et al. An electronic surveillance tool for catheter-associated urinary tract infection in intensive care units. Am J Infect Control. 2015;43(6):592-9. https://doi.org/10.1016/j. ajic.2015.02.019 PMID: 25840717

39. Inacio MC, Paxton EW, Chen Y, Harris J, Eck E, Barnes S, et al. Leveraging electronic medical records for surveillance of surgical site infection in a total joint replacement population. Infect Control Hosp Epidemiol. 2011;32(4):351-9. https://doi. org/10.1086/658942 PMID: 21460486

40. Kaiser AM, de Jong E, Evelein-Brugman SF, Peppink JM, Vandenbroucke-Grauls CM, Girbes AR. Development of triggerbased semi-automated surveillance of ventilator-associated pneumonia and central line-associated bloodstream infections in a Dutch intensive care. Ann Intensive Care. 2014;4(1):40. https://doi.org/10.1186/s13613-014-0040-x PMID: 25646148

41. King C, Aylin P, Moore LS, Pavlu J, Holmes A. Syndromic surveillance of surgical site infections--a case study in coronary artery bypass graft patients. J Infect. 2014;68(1):2331. https://doi.org/10.1016/j.jinf.2013.08.017 PMID: 24001609

42. Klompas M, Kleinman K, Platt R. Development of an algorithm for surveillance of ventilator-associated pneumonia with electronic data and comparison of algorithm results with clinician diagnoses. Infect Control Hosp Epidemiol. 2008;29(1):31-7. https://doi.org/10.1086/524332 PMID: 18171184

43. Klein Klouwenberg PM, van Mourik MS, Ong DS, Horn J, Schultz MJ, Cremer OL, et al. MARS Consortium. Electronic implementation of a novel surveillance paradigm for ventilatorassociated events. Feasibility and validation. Am J Respir Crit Care Med. 2014;189(8):947-55. https://doi.org/10.1164/ rccm.201307-13760C PMID: 24498886

44. Knepper BC, Young H, Jenkins TC, Price CS. Time-saving impact of an algorithm to identify potential surgical site infections. Infect Control Hosp Epidemiol. 2013;34(10):1094-8. https:// doi.org/10.1086/673154 PMID: 24018927

45. Knepper BC, Young H, Reese SM, Savitz LA, Price CS. Identifying colon and open reduction of fracture surgical site infections using a partially automated electronic algorithm. Am J Infect Control. 2014;42(10) Suppl;S291-5. https://doi. org/10.1016/j.ajic.2014.05.015 PMID: 25239724

46. Kulaylat AN, Engbrecht BW, Rocourt DV, Rinaldi JM, Santos MC, Cilley RE, et al. Measuring Surgical Site Infections in Children: Comparing Clinical, Electronic, and Administrative Data. J Am Coll Surg. 2016;222(5):823-30. https://doi.org/10.1016/j. jamcollsurg.2016.01.004 PMID: 27010586

47. Leclère $B$, Lasserre $C$, Bourigault $C$, Juvin ME, Chaillet MP, Mauduit N, et al. SSI Study Group. Matching bacteriological and medico-administrative databases is efficient for a computer-enhanced surveillance of surgical site infections: retrospective analysis of 4,400 surgical procedures in a French university hospital. Infect Control Hosp Epidemiol. 2014;35(11):1330-5. https://doi.org/10.1086/678422 PMID: 25333426

48. Leth RA, Møller JK. Surveillance of hospital-acquired infections based on electronic hospital registries. J Hosp Infect. 2006;62(1):71-9. https://doi.org/10.1016/j.jhin.2005.04.002 PMID: 16099539

49. Leth RA, Nørgaard M, Uldbjerg N, Thomsen RW, Møller JK. Surveillance of selected post-caesarean infections based on electronic registries: validation study including post-discharge infections. J Hosp Infect. 2010;75(3):200-4. https://doi. org/10.1016/j.jhin.2009.11.018 PMID: 20381909

50. Lo YS, Lee WS, Liu CT. Utilization of electronic medical records to build a detection model for surveillance of healthcare-associated urinary tract infections. J Med Syst. 2013;37(2):9923. https://doi.org/10.1007/s10916-012-9923-2 PMID: 23321977

51. Mann T, Ellsworth J, Huda N, Neelakanta A, Chevalier T, Sims $\mathrm{KL}$, et al. Building and validating a computerized algorithm for surveillance of ventilator-associated events. Infect Control Hosp Epidemiol. 2015;36(9):999-1003. https://doi. org/10.1017/ice.2015.127 PMID: 26072660

52. Mendonça EA, Haas J, Shagina L, Larson E, Friedman C. Extracting information on pneumonia in infants using natural language processing of radiology reports. J Biomed Inform. 2005;38(4):314-21. https://doi.org/10.1016/j.jbi.2005.02.003 PMID: 16084473
53. Michelson JD, Pariseau JS, Paganelli WC. Assessing surgical site infection risk factors using electronic medical records and text mining. Am J Infect Control. 2014;42(3):333-6. https://doi. org/10.1016/j.ajic.2013.09.007 PMID: 24406258

54. Moro ML, Morsillo F. Can hospital discharge diagnoses be used for surveillance of surgical-site infections? J Hosp Infect. 2004;56(3):239-41. https://doi.org/10.1016/j.jhin.2003.12.022 PMID: 15003675

55. Nuckchady D, Heckman MG, Diehl NN, Creech T, Carey D, Domnick R, et al. Assessment of an automated surveillance system for detection of initial ventilator-associated events. Am J Infect Control. 2015;43(10):1119-21. https://doi.org/10.1016/j. ajic.2015.05.040 PMID: 26164766

56. Perdiz LB, Yokoe DS, Furtado GH, Medeiros EA. Impact of an Automated Surveillance to Detect Surgical-Site Infections in Patients Undergoing Total Hip and Knee Arthroplasty in Brazil. Infect Control Hosp Epidemiol. 2016;37(8):991-3. https://doi. org/10.1017/ice.2016.86 PMID: 27072598

57. Pokorny L, Rovira A, Martín-Baranera M, Gimeno C, AlonsoTarrés C, Vilarasau J. Automatic detection of patients with nosocomial infection by a computer-based surveillance system: a validation study in a general hospital. Infect Control Hosp Epidemiol. 2006;27(5):500-3. https://doi.org/10.1086/502685 PMID: 16671032

58. Redder JD, Leth RA, Møller JK. Incidence rates of hospitalacquired urinary tract and bloodstream infections generated by automated compilation of electronically available healthcare data. J Hosp Infect. 2015;91(3):231-6. https://doi. org/10.1016/j.jhin.2015.05.011 PMID: 26162918

59. Ridgway JP, Sun X, Tabak YP, Johannes RS, Robicsek A. Performance characteristics and associated outcomes for an automated surveillance tool for bloodstream infection. Am I Infect Control. 2016;44(5):567-71. https://doi.org/10.1016/j. ajic.2015.12.044 PMID: 26899530

6o. Rocha BH, Christenson JC, Pavia A, Evans RS, Gardner RM. Computerized detection of nosocomial infections in newborns. Proc Annu Symp Comput Appl Med Care. 1994;684-8. PMID: 7950013

61. Stamm AM, Bettacchi CJ. A comparison of 3 metrics to identify health care-associated infections. Am J Infect Control. 2012;40(8):688-91. https://doi.org/10.1016/j.ajic.2012.01.033 PMID: 22727246

62. Stevens JP, Silva G, Gillis J, Novack V, Talmor D, Klompas $M$, et al. Automated surveillance for ventilator-associated events. Chest. 2014;146(6):1612-8. https://doi.org/10.1378/ chest.13-2255 PMID: 25451350

63. Streefkerk RHRA, Borsboom GJ, van der Hoeven CP, Vos MC, Verkooijen RP, Verbrugh HA. Evaluation of an algorithm for electronic surveillance of hospital-acquired infections yielding serial weekly point prevalence scores. Infect Control Hosp Epidemiol. 2014;35(7):888-90. https://doi. org/10.1086/676869 PMID: 24915222

64. Streefkerk RHRA, Moorman PW, Parlevliet GA, van der Hoeven $\mathrm{C}$, Verbrugh HA, Vos MC, et al. An automated algorithm to preselect patients to be assessed individually in point prevalence surveys for hospital-acquired infections in surgery. Infect Control Hosp Epidemiol. 2014;35(7):886-7. https://doi. org/10.1086/676868 PMID: 24915221

65. Tanushi H, Kvist M, Sparrelid E. Detection of healthcareassociated urinary tract infection in Swedish electronic health records. Stud Health Technol Inform. 2014;207:330-9. PMID: 25488239

66. Trick WE, Zagorski BM, Tokars JI, Vernon MO, Welbel SF, Wisniewski MF, et al. Computer algorithms to detect bloodstream infections. Emerg Infect Dis. 2004;10(9):1612-20. https://doi.org/10.3201/eid1009.030978 PMID: 15498164

67. Tseng YJ, Wu JH, Lin HC, Chen MY, Ping XO, Sun CC, et al. A Web-Based, Hospital-Wide Health Care-Associated Bloodstream Infection Surveillance and Classification System: Development and Evaluation. JMIR Med Inform. 2015;3(3):e31. https://doi.org/10.2196/medinform.4171 PMID: 26392229

68. Tseng YJ, Wu JH, Lin HC, Chiu HJ, Huang BC, Shang RJ, et al. Rule-based healthcare-associated bloodstream infection classification and surveillance system. Stud Health Technol Inform. 2013;186:145-9. PMID: 23542986

69. van Mourik MS, Groenwold RH, Berkelbach van der Sprenkel JW, van Solinge WW, Troelstra A, Bonten MJ. Automated detection of external ventricular and lumbar drain-related meningitis using laboratory and microbiology results and medication data. PLoS One. 2011;6(8):e22846. https://doi. org/10.1371/journal.pone.0022846 PMID: 21829659

70. van Mourik MS, Troelstra A, Moons KG, Bonten MJ. Accuracy of hospital discharge coding data for the surveillance of drain-related meningitis. Infect Control Hosp Epidemiol. 2013;34(4):433-6. https://doi.org/10.1086/669867 PMID: 23466919 
71. van Mourik MSM, Moons KG, van Solinge WW, Berkelbachvan der Sprenkel JW, Regli L, Troelstra A, et al. Automated detection of healthcare associated infections: external validation and updating of a model for surveillance of drainrelated meningitis. PLoS One. 2012;7(12):e51509. https://doi. org/10.1371/journal.pone.0051509 PMID: 23236510

72. van Mourik MSM, Troelstra A, Berkelbach van der Sprenkel JW, van der Jagt-Zwetsloot MC, Nelson JH, Vos P, et al. Validation of an automated surveillance approach for drain-related meningitis: a multicenter study. Infect Control Hosp Epidemiol. 2015;36(1):65-75. https://doi.org/10.1017/ice.2014.5 PMID: 25627763

73. Venable A, Dissanaike S. Is automated electronic surveillance for healthcare-associated infections accurate in the burn unit? J Burn Care Res. 2013;34(6):591-7. https://doi.org/10.1097/ BCR.obo13e3182a2aaof PMID: 24121803

74. Wald HL, Bandle B, Richard A, Min S. Accuracy of electronic surveillance of catheter-associated urinary tract infection at an academic medical center. Infect Control Hosp Epidemiol. 2014;35(6):685-91. https://doi.org/10.1086/529079 PMID: 24799645

75. Woeltje KF, Butler AM, Goris AJ, Tutlam NT, Doherty JA, Westover MB, et al. Automated surveillance for central lineassociated bloodstream infection in intensive care units. Infect Control Hosp Epidemiol. 2008;29(9):842-6. https://doi. org/10.1086/590261 PMID: 18713052

76. Woeltje KF, McMullen KM, Butler AM, Goris AJ, Doherty JA. Electronic surveillance for healthcare-associated central line-associated bloodstream infections outside the intensive care unit. Infect Control Hosp Epidemiol. 2011;32(11):1086-90. https://doi.org/10.1086/662181 PMID: 22011535

77. Yu TH, Hou YC, Lin KC, Chung KP. Is it possible to identify cases of coronary artery bypass graft postoperative surgical site infection accurately from claims data? BMC Med Inform Decis Mak. 2014;14(1):42. https://doi.org/10.1186/1472-6947-14-42 PMID: 24884488

78. Bond J, Issa M, Nasrallah A, Bahroloomi S, Blackwood RA. Comparing administrative and clinical data for central line associated blood stream infections in Pediatric Intensive Care Unit and Pediatric Cardiothoracic Intensive Care Unit. Infect Dis Rep. 2016;8(3):58-62. https://doi.org/10.4081/idr.2016.6275

79. Condell O, Gubbels S, Nielsen J, Espenhain L, Frimodt-Møller N, Engberg J, et al. Automated surveillance system for hospitalacquired urinary tract infections in Denmark. J Hosp Infect. 2016;93(3):290-6. https://doi.org/10.1016/j.jhin.2016.04.001 PMID: 27157847

80. Gubbels S, Nielsen J, Voldstedlund M, Kristensen B, Schønheyder HC, Ellermann-Eriksen S, et al. National automated surveillance of hospital-acquired bacteremia in Denmark using a computer algorithm. Infect Control Hosp Epidemiol. 2017;38(5):559-66. https://doi.org/10.1017/ ice.2017.1 PMID: 28274300

81. Hebert C, Flaherty J, Smyer J, Ding J, Mangino JE. Development and validation of an automated ventilator-associated event electronic surveillance system: A report of a successful implementation. Am J Infect Control. 2018;46(3):316-21. https://doi.org/10.1016/j.ajic.2017.09.006 PMID: 29132696

82. Leal JR, Gregson DB, Church DL, Henderson EA, Ross T, Laupland KB. The Validation of a Novel Surveillance System for Monitoring Bloodstream Infections in the Calgary Zone. Can J Infect Dis Med Microbiol. 2016;2016:2935870. https://doi. org/10.1155/2016/2935870 PMID: 27375749

83. Marra AR, Alkatheri M, Edmond MB. Catheter-Associated Urinary Tract Infection: Utility of the ICD-10 Metric as a Surrogate for the National Healthcare Safety Network (NHSN) Surveillance Metric. Infect Control Hosp Epidemiol. 2017;38(4):506-7. https://doi.org/10.1017/ice.2016.335 PMID: 28137321

84. Pindyck T, Gupta K, Strymish J, Itani KM, Carter ME, Suo Y, et al. Validation of an electronic tool for flagging surgical site infections based on clinical practice patterns for triaging surveillance: Operational successes and barriers. Am J Infect Control. 2018;46(2):186-90. https://doi.org/10.1016/j. ajic.2017.08.026 PMID: 29031434

85. Sips ME, Bonten MJM, van Mourik MSM. Semiautomated Surveillance of Deep Surgical Site Infections After Primary Total Hip or Knee Arthroplasty. Infect Control Hosp Epidemiol. 2017;38(6):732-5. https://doi.org/10.1017/ice.2017.37 PMID: 28366180

86. Streefkerk HRA, Lede IO, Eriksson JL, Meijling MG, van der Hoeven CP, Wille JC, et al. Internal and External Validation of a Computer-Assisted Surveillance System for Hospital-Acquired Infections in a 754-Bed General Hospital in the Netherlands. Infect Control Hosp Epidemiol. 2016;37(11):1355-60. https:// doi.org/10.1017/ice.2016.159 PMID: 27488723
87. Wenzel RP, Streed SA. Surveillance and use of computers in hospital infection control. J Hosp Infect. 1989;13(3):217-29. https://doi.org/10.1016/0195-6701(89)90002-9 PMID: 2567751

88. Peterson LR, Brossette SE. Hunting health care-associated infections from the clinical microbiology laboratory: passive, active, and virtual surveillance. J Clin Microbiol. 2002;40(1):14. https://doi.org/10.1128/JCM.40.1.1-4.2002 PMID: 11773083

89. Leal J, Laupland KB. Validity of electronic surveillance systems: a systematic review. J Hosp Infect. 2008;69(3):220-9. https:// doi.org/10.1016/j.jhin.2008.04.030 PMID: 18550211

90. Freeman R, Moore LS, García Álvarez L, Charlett A, Holmes A. Advances in electronic surveillance for healthcareassociated infections in the 21st Century: a systematic review. J Hosp Infect. 2013;84(2):106-19. https://doi.org/10.1016/j. jhin.2012.11.031 PMID: 23648216

91. Penz JFE, Wilcox AB, Hurdle JF. Automated identification of adverse events related to central venous catheters. J Biomed Inform. 2007;40(2):174-82. https://doi.org/10.1016/j. jbi.2006.06.003 PMID: 16901760

92. de Bruin IS, Seeling W, Schuh C. Data use and effectiveness in electronic surveillance of healthcare associated infections in the 21st century: a systematic review. J Am Med Inform Assoc. 2014;21(5):942-51. https://doi.org/10.1136/ amiajnl-2013-002089 PMID: 24421290

93. Cato KD, Cohen B, Larson E. Data elements and validation methods used for electronic surveillance of health careassociated infections: a systematic review. Am J Infect Control. 2015;43(6):600-5. https://doi.org/10.1016/j.ajic.2015.02.006 PMID: 26042848

94. Rijksinstituut voor Volksgezondheid en Milieu (RIVM). Referentiecijfers 2014 t/m 2017: Prevalentieonderzoek ziekenhuizen. [Reference numbers 2014 to 2017 included: hospital prevalence study]. Dutch. Bilthoven: RIVM; Nov 2018. Available from: https://www.rivm.nl/documenten/ prezies-referentiecijfers-prevalentie-2017

95. Olsen L, Aisner D, McGinnis JM, editors. The learning healthcare system: workshop summary; Roundtable on Evidence-Based Medicine. Washington, DC: The National Academies Press; 2007. Available from: https://www.nap.edu/ $\mathrm{read} / 11903 / \mathrm{chapter} / 1$

96. Celi LA, Marshall JD, Lai Y, Stone DJ. Disrupting Electronic Health Records Systems: The Next Generation. JMIR Med Inform. 2015;3(4):e34-34. https://doi.org/10.2196/ medinform.4192 PMID: 26500106

97. Evans RS, Abouzelof RH, Taylor CW, Anderson V, Sumner $\mathrm{S}$, Soutter $\mathrm{S}$, et al. Computer surveillance of hospitalacquired infections: a 25 year update. AMIA Annu Symp Proc. 2009;2009:178-82. PMID: 20351845

\section{License, supplementary material and copyright}

This is an open-access article distributed under the terms of the Creative Commons Attribution (CC BY 4.0) Licence. You may share and adapt the material, but must give appropriate credit to the source, provide a link to the licence and indicate if changes were made.

Any supplementary material referenced in the article can be found in the online version.

This article is copyright of the authors or their affiliated institutions, 2020. 